\title{
Solvent primitive model of an electric double layer in slit-like pores: microscopic structure, adsorption and capacitance from a density functional approach
}

\author{
O. Pizid1:; S. Sokołowsk $2^{2}$ \\ ${ }^{1}$ Instituto de Química, Universidad Nacional Autonoma de México, Circuito Exterior, Ciudad Universitaria, \\ 04510 México, D.F., México \\ 2 Department for the Modelling of Physico-Chemical Processes, Maria Curie-Sklodowska University, \\ Gliniana 33, Lublin, Poland
}

Received January 27, 2014, in final form February 23, 2014

\begin{abstract}
We investigate the electric double layer formed between charged walls of a slit-like pore and a solvent primitive model (SPM) for electrolyte solution. The recently developed version of the weighted density functional approach for electrostatic interparticle interaction is applied to the study of the density profiles, adsorption and selectivity of adsorption of ions and solvent species. Our principal focus, however, is in the dependence of differential capacitance on the applied voltage, on the electrode and on the pore width. We discuss the properties of the model with respect to the behavior of a primitive model, i.e., in the absence of a hard-sphere solvent. We observed that the differential capacitance of the SPM on the applied electrostatic potential has the camel-like shape unless the ion fraction is high. Moreover, it is documented that the dependence of differential capacitance of the SPM on the pore width is oscillatory, which is in close similarity to the primitive model.
\end{abstract}

Key words: solvent primitive model, density functional, electrolyte solutions, adsorption, differential capacitance

PACS: $61.20 . G y, 61.20 . Q g, 65.20 . J k, 68.08 .-p, 68.43 . D e$

\section{Introduction}

The most frequently applied microscopic modelling for the electric double layer (EDL) formed at an interface between a charged solid surface involves the primitive model (PM) of the fluid ionic subsystem. Namely, it is assumed that ions are charged hard spheres immersed into a dielectric continuum having a certain dielectric constant. This very simplified model, compared to real systems in laboratory, has been used for the development and testing of theoretical approaches, as well as to explain experimental observations.

In the theoretical approaches, the dielectric discontinuity at the electrode-electrolyte interface is usually neglected. Another simplification commonly used in the problem of adsorption of PM electrolyte solutions into slit-like pores is to assume that the dielectric constant of the bulk fluid and inside a pore is the same. These comments just illustrate how far the present theoretical modelling is from an entirely satisfactory description of the EDL problems.

One step forward can be made by considering the solvent primitive model (SPM) rather than the PM in the EDL problems. The essence of the SPM is to take into account the effects of excluded volume, due to the presence of solvent molecules (most frequently considered as hard spheres) that are neglected in the PM. First attempts to investigate the SPM at a charged surface have been undertaken in references [1, 2]. More comprehensive efforts to explore the properties of the SPM at charged surfaces have been carried out using a density functional theory [3, 4] and Monte Carlo computer simulations [5, 6]. For

\footnotetext{
*E-mail: oapizio@gmail.com
} 
the purposes of our study, it is worth mentioning that Tang et al. [3] used Tarazona's weighted density method to describe the hard sphere interaction, while the electrostatic contribution to the free energy functional was modelled assuming that the residual part of the direct correlation functions of nonuniform fluid is the same as in a bulk ionic system. On the other hand, in their recent investigation, Oleksy and Hansen [4] used a version of the density functional approach in which the electrostatic correlation contribution was neglected. In the same context, quite recently the SPM has been used to describe certain aspects of partitioning of electrolyte solutions through semipermeable membranes [7-9]. The importance of such sophistication of modelling, in spite of intrinsic impossibility to describe dielectric properties of the solvent medium, has been documented.

The present state of knowledge regarding the properties of the SPM electric double layer is still incomplete, in particular, concerning the problem of adsorption of electrolyte solutions in the slit-like pores, where an overlap of structures formed at two pore walls can cause some peculiarities of the density profiles, adsorption, dependence of the accumulated charge on the applied voltage and differential capacitance. The overlap of double layers formed at each wall has been involved in the interpretation of recent experimental observations of the dependence of the capacitance of an electrolyte solution on the pore width [10, 11], exhibiting a maximum for a particular very narrow pore of the width slightly larger than the value of the diameter of ions. Computer simulations performed for primitive type models, though with sophistication of the internal structure of ions in some cases, have confirmed the experimental results and provided a certain explanation of the peculiarities of the behavior of the differential capacitance in narrow pores [12-16].

The study of the effect of the differential capacitance of the SPM electric double layer on the value of electrostatic potential, on the pore walls and on the pore width is the principal issue of the present communication. To investigate this model, we use the recent successful weighted density functional approach proposed for a restricted primitive model of electrolyte solutions in contact with charged solid surface [17, 18]. Here, this approach is extended to a mixture of positive and negative ions and hard spheres confined in slit-like pores. In doing this, we use the recent developments dealing with the study of a similar problem, although at the level of the PM for electrolyte solutions in slit-like pores [19-22].

\section{The model and theory}

The SPM under consideration consists of three species, i.e., positive and negative ions $(+,-)$ and solvent molecules mimicked as hard spheres (hs). For the sake of simplicity, in this work we assume that the diameters of all species are the same, $\sigma_{+}=\sigma_{-}=\sigma_{\mathrm{hs}}=\sigma$. The valencies of cations and anions are the same $Z^{(+)}=\left|Z^{(-)}\right|=Z$. Moreover, we restrict to univalent ions in what follows, i.e., $Z=1$. The interactions between species are as follows:

$$
u^{(\alpha \gamma)}(r)= \begin{cases}\infty, & r<\sigma, \\ \frac{e^{2} Z^{(\alpha)} Z^{(\gamma)}}{4 \pi \epsilon \epsilon_{0}} \frac{1}{r}, & r>\sigma,\end{cases}
$$

where $\alpha, \gamma=+,-$, hs; $e$ denotes the magnitude of elementary charge, $\epsilon$ is the relative permittivity and $\epsilon_{0}$ is the permittivity of the vacuum. Also $Z^{(\mathrm{hs})}=0$, thus the solvent is just the fluid of hard spheres.

The mixture of three components is confined in a slit-like pore of the width $H$. The interaction of ions with the pore walls is described by the potential $v^{(\alpha)}(z)=v^{\prime(\alpha)}(z)=v^{\prime(\alpha)}(H-z)(\alpha=+,-)$,

$$
\nu^{\prime(\alpha)}(z)=v_{\mathrm{hw}}(z)+v_{\mathrm{el}}^{(\alpha)}(z)
$$

where $v_{\mathrm{hw}}(z)$ is the hard-wall potential

$$
v_{\mathrm{hw}}(z)= \begin{cases}\infty, & \text { for } z<\sigma / 2 \text { and } z>H-\sigma / 2, \\ 0, & \text { otherwise }\end{cases}
$$

and

$$
\beta v_{\mathrm{el}}^{(\alpha)}(z)=-2 \pi l_{\mathrm{B}} Q Z^{(\alpha)} z
$$

is the Coulomb potential. In the above $\beta=1 / k T, Q e$ is the surface charge density of the wall, $l_{\mathrm{B}}=$ $e^{2} /\left(4 \pi k T \epsilon \epsilon_{0}\right)$ denotes the Bjerrum length. Energetic aspects of interactions between ions for the model 
in hand are given in terms of reduced temperature $T_{\mathrm{el}}^{*}=\sigma / l_{\mathrm{B}}$. We assume that the interaction of solvent species with the pore walls, $v^{(\mathrm{hs})}(z)=v^{\prime(\mathrm{hs})}(z)=v^{\prime(\mathrm{hs})}(H-z)$, is given in the form of Yukawa potential,

$$
\nu^{\prime(\mathrm{hs})}(z)= \begin{cases}\infty, & \text { for } z<\sigma / 2 \text { and } z>H-\sigma / 2, \\ \varepsilon_{\mathrm{gs}} \exp \left[-\lambda_{\mathrm{gs}}(z-\sigma / 2)\right] / z, & \text { otherwise. }\end{cases}
$$

The confined mixture is in equilibrium with the bulk mixture composed of the same components. The bulk dimensionless densities of the species $\alpha=+,-$, hs are $\rho_{\alpha}^{*}=\rho_{\alpha} \sigma^{3}\left(\rho_{\text {ion }}^{*}=\rho_{+}^{*}+\rho_{-}^{*}\right)$.

We use the density functional approach, described more in detail in our recent works, see e.g., references [19, 20, 23]. In essence, we construct a thermodynamic potential for the system and then the equilibrium density profiles are obtained by minimizing the thermodynamic potential,

$$
\Omega=F+\sum_{\alpha=+,-, \mathrm{hs}} \int \mathrm{d} \mathbf{r}\left[v^{(\alpha)}(z) \rho^{(\alpha)}(z)-\mu_{\alpha}\right]+\int \mathrm{d} \mathbf{r} q(z) \Psi(z) .
$$

In the above $\rho^{(\alpha)}(z)$ and $\mu_{\alpha}$ are the local density and the chemical potential of the species $\alpha$, respectively, $F$ is the free energy functional and $q(z)$ is the charge density,

$$
q(z) / e=\sum_{\alpha=+,-} Z^{(\alpha)} \rho^{(\alpha)}(z)
$$

The electrostatic $\Psi(z)$ satisfies the Poisson equation,

$$
\nabla^{2} \Psi(z)=-\frac{4 \pi}{\epsilon \epsilon_{0}} q(z) .
$$

The solution of differential equation (8) for the slit-pore geometry with walls of equal charge is perfomed similarly to reference [24], where the model is different, however. Moreover, the method of solving the Poisson equation for a set of interconnected slit-like pores with permeable walls was explained and analysed in every detail in the recent work by Kovacs et al. [25]. For the model of a single slit defined by equations (2)-(5) in the present study, the solution requires the choice of the boundary condition, namely of the value of the electrostatic potential at a wall, $V_{0}=\Psi(z=0)=\Psi(z=H)$.

From the electro-neutrality condition of the system it follows that

$$
Q+\int \mathrm{d} z q(z)=0
$$

where $Q e$ is the surface charge density of the wall as we have already mentioned above.

The free energy of the system, $F$, is the sum of the ideal, $F_{\mathrm{id}}$, hard sphere, $F_{\mathrm{hs}}$ and residual electrostatic excess contribution, $F_{\text {el }}$, arising from the coupling between electrostatic and hard-sphere interactions. The ideal part of the free energy, $F_{\text {id }}$, is known exactly,

$$
F_{\text {id }} / k T=\sum_{\alpha=a, c, \mathrm{hs}} \int \mathrm{d} \mathbf{r} \rho^{(\alpha)}(z)\left[\ln \left(\rho^{(\alpha)}(z)\right)-1\right] .
$$

The excess free energy due to hard sphere interactions between the species +,-, and hs, $F_{\mathrm{hs}}$, is taken from the fundamental measure theory [26-30]. The details of the White Bear version of the fundamental measure theory are given in references [26-28] Finally, the residual electrostatic contribution $F_{\mathrm{el}}$ is described by using the so-called "weighted correlation approach", WCA- $k^{2}$ approximation, developed for nonuniform RPM ionic fluids by Wang et al. [17, 18] based on the analytic solution of the mean spherical approximation, cf. also reference [19]. The expressions used in the present study are given by equations (11)-(14) of our recent work [19]. They are omitted to avoid the unnecessary repetition.

At equilibrium, the density profiles minimize the thermodynamic potential $\Omega$, i.e.,

$$
\frac{\delta \Omega}{\delta \rho^{(\alpha)}(\mathbf{r})}=0, \quad \alpha=+,-, \text { hs. }
$$

The resulting density profile equations can be straightforwardly derived by modifying those given in references [4, 17-19]

As we have mentioned above, the adsorption system is in equilibrium with the bulk SPM mixture, this equilibrium being determined by the equality of chemical potentials of each species in the bulk phase and in the pore. The bulk densities of ionic species satisfy the electro-neutrality condition $Z^{(+)} \rho_{+}+Z^{(-)} \rho_{-}=0$. 


\section{Results}

Let us now specify a set of parameters of the model we study below. As already mentioned in the introduction, we restrict our attention to the model of equal diameters of all the species involved. Actually, we performed calculations for the model with a larger diameter of solvent species compared to the diameter of ions, but qualitatively the trends observed are very similar to those discussed below. The distance from the wall and pore width are given in reduced units, $z^{*}=z / \sigma$ and $H^{*}=H / \sigma$, respectively. Also, the electrostatic potential at the wall is considered in reduced units, $V^{*}=e V_{0} / k T$. Another introductory comment concerns the interaction between solvent hard sphere species and pore walls. It has been written in the form of Yukawa interaction. However, in the present study we just consider weakly adsorbing walls, $k T / \varepsilon_{\mathrm{gs}}=1$ and $\lambda_{\mathrm{gs}}=3$. This interaction has been introduced having in mind a possible extension of the SPM model in order to take into account the attractive interaction between solute particles in the spirit of works by Oleksy and Hansen [4, 31-33]. On the other hand, our interest is in a dense fluid with high fraction of solvent species and low ion content. Thus, in the majority of numerical calculations, the solvent bulk density is taken to be $\rho_{\mathrm{hs}}^{*}=0.5$.

\subsection{Density profiles and adsorption}

We begin the discussion by considering the microscopic structure and the resulting thermodynamic properties. The evolution of the density profile of a hard sphere solvent of the SPM with an increasing electrostatic potential on the wall is shown in figure 1. It can be seen that the contact value of the profile $\rho_{\mathrm{hs}}(z)$ decreases with an increasing $V^{*}$, showing that hard spheres are expelled from the vicinity of the wall. The density of the second layer at $z^{*}=2.5$ increases with an increasing $V^{*}$, reaches a maximum value at $V^{*}=30.8$ and then slightly decreases with a further increase of the electrostatic potential. This proves that hard sphere solvent particles are again slightly expelled from the second layer at the expense of a weakly increasing density closer to the pore center. These trends are due to accumulation and simultaneous separation of ion species close to the charged surface of the pore, figure 2

The density of counter-ions substantially increases close to the pore walls while the density of coions decreases at the contact and in the pore walls vicinity with an increasing $V^{*}$. However, structural changes also occur in the second layer around $z^{*}=2.5$. In this layer, the co-ion density increases while opposite trends are seen for the counter-ions. It seems, however, that the presence of hard sphere solvent
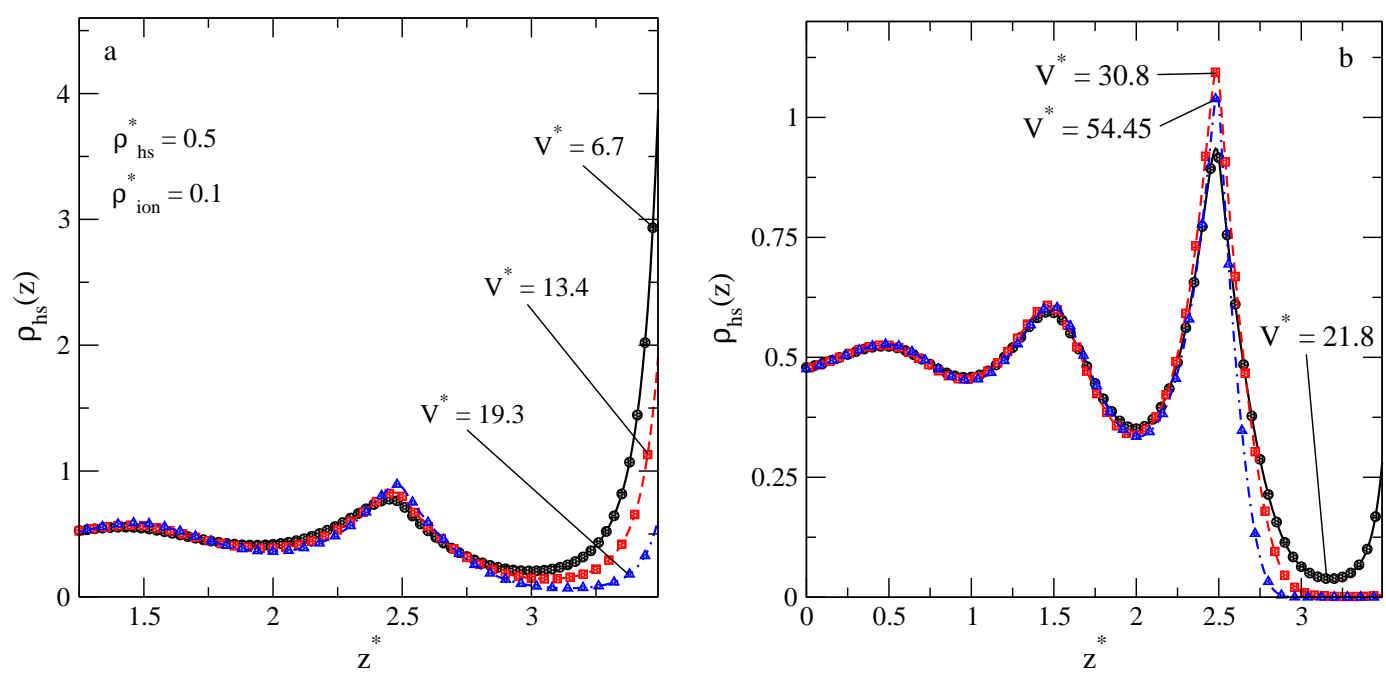

Figure 1. (Color online) Evolution of the density profiles of hard sphere species, $\rho_{\mathrm{hs}}(z)$, of the SPM, with the applied electrostatic potential on the wall, $V^{*}$, at bulk density, $\rho_{\mathrm{hs}}^{*}=0.5, \rho_{\mathrm{ion}}^{*}=0.1$, in the slit-like pore of the width $H^{*}=8$. The energetic parameters of the SPM are $T_{\mathrm{el}}^{*}=0.15, k T / \varepsilon_{\mathrm{gs}}=1.0$ here and in all the subsequent figures. 

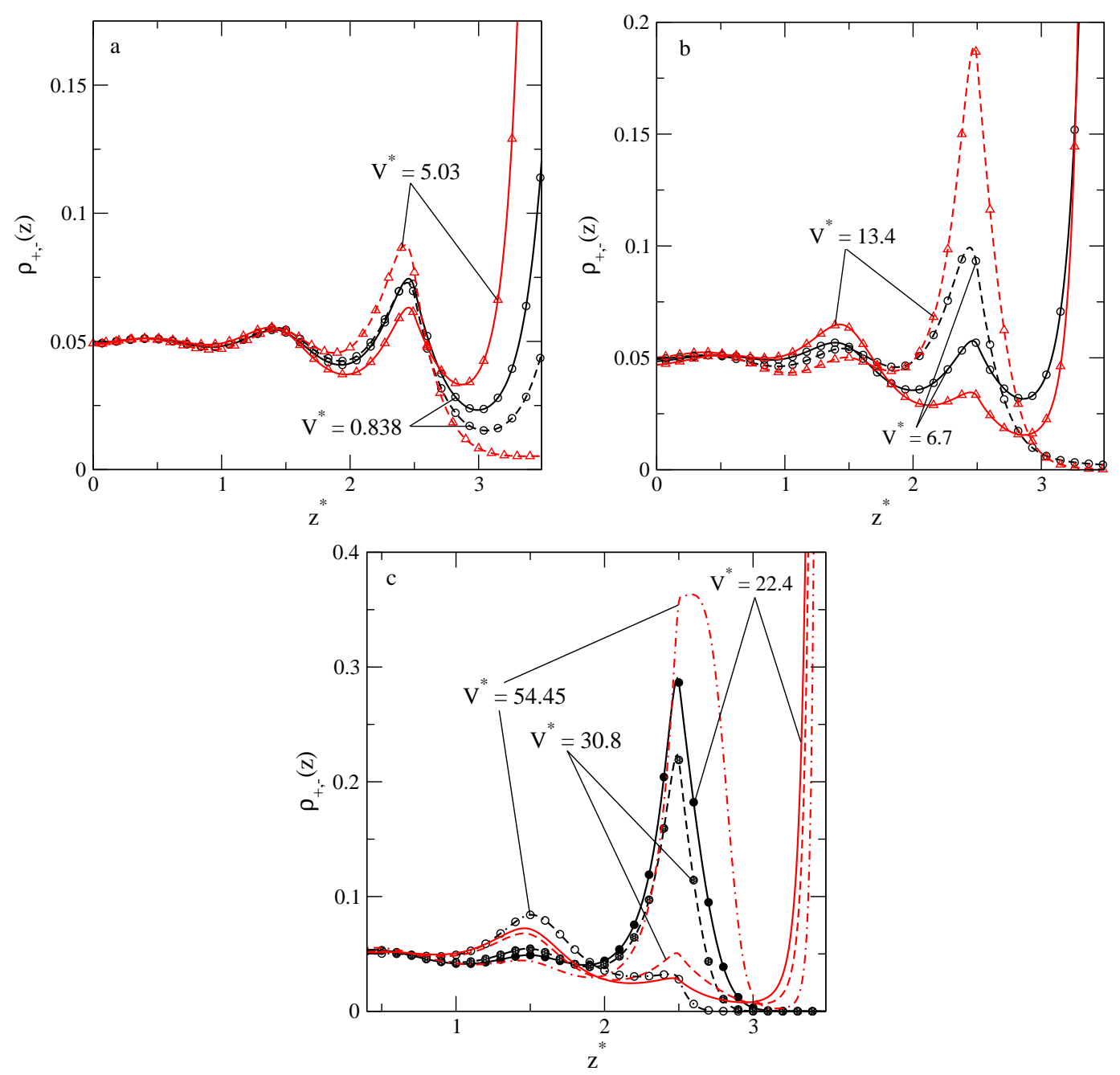

Figure 2. (Color online) Evolution of the density profiles of each ion species, $\rho_{+,-}(z)$, of the SPM, with the electrostatic potential applied to the wall, $V^{*}$. The system is the same as in figure 1

species in the pore center promotes the separation of ions of the opposite charge close to the wall, thus playing a role of supporting the external field effects.

The trends of behavior of the average density of species in the pore with an increasing electrostatic potential are illustrated in figure 3 Excess adsorption of the species is defined as common:

$$
A_{\alpha}^{\mathrm{ex}}=\int \mathrm{d} z\left[\rho_{\alpha}(z)-\rho_{\alpha}\right]
$$

and the average density of the species is as follows:

$$
\left\langle\rho_{\alpha}\right\rangle_{H}=\frac{1}{H} \int \mathrm{d} z \rho_{\alpha}(z)
$$

From the panel (a) of this figure we learn that the excess adsorption of a hard sphere solvent substantially decreases with an increasing electrostatic potential and is negative in almost entire range of $V^{*}$. In all three cases considered, we kept constant the total density of the bulk solution at $\rho_{\text {hs }}+\rho_{\text {ion }}=0.6$ and changed its composition by decreasing the ion density in the systems 1,2 , and 3 . The curves behave differently at low, intermediate and high $V^{*}$. In a narrow region of rather small $V^{*}$ and at high values of $V^{*}$, the lowest excess adsorption is observed for the system 3 that has the lowest fraction of ions in the 

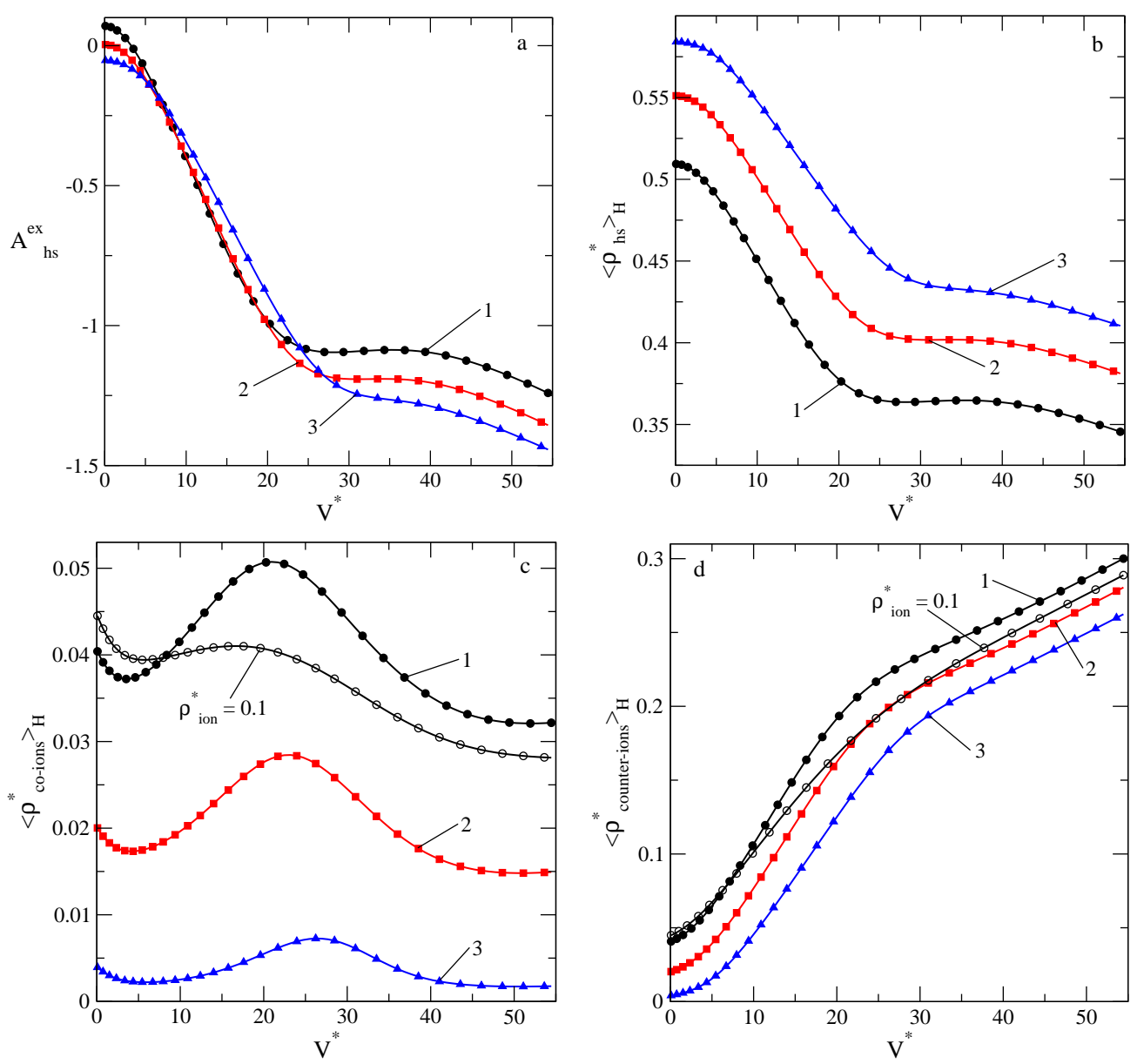

Figure 3. (Color online) Excess adsorption and average density of hard sphere species of the SPM in the slit like pore $H^{*}=8$, panels (a) and (b), respectively. Average density of co-ions [panel (c)] and of counterions [panel (d)] in this pore. The nomenclature of systems is the following: $1-\rho_{\mathrm{hs}}^{*}=0.5, \rho_{\mathrm{ion}}^{*}=0.1 ; 2-$ $\rho_{\mathrm{hs}}^{*}=0.55, \rho_{\text {ion }}^{*}=0.05 ; 3-\rho_{\mathrm{hs}}^{*}=0.59, \rho_{\text {ion }}^{*}=0.01$.

bulk phase. The average density of hard sphere species [panel (b)] decreases with an increasing $V^{*}$, its dependence on $V^{*}$ being non-monotonous, however.

This behavior of the excess adsorption and of the average density of solvent species is due to the changes of the average density (and distribution of ions) in the pore under the effect of external electric field. In particular, the behavior of the average density of co-ions [panel (c)] with an increasing $V^{*}$ having a maximum in the interval between 20 and 25 can be traced back to the corresponding density profiles showing how the co-ions are expelled from the vicinity of the wall and how they form a relatively dense second layer. Again, changes of the structure discussed in terms of the curves in figure 2 are manifest due to the different rate of growth at low and high $V^{*}$ of the average density of counter-ions [panel (d) of figure 3. Most important, changes of the density of ion species and changes of distribution of solvent species upon increasing the electrostatic potential cause the changes of the dependence of the charge in the pore and consequently the changes in the shape of the differential capacitance.

\subsection{Differential capacitance}

The differential capacitance,

$$
C_{\mathrm{D}}=\left(\frac{\partial Q}{\partial V_{0}}\right)_{H, T, \mu_{\alpha}},
$$



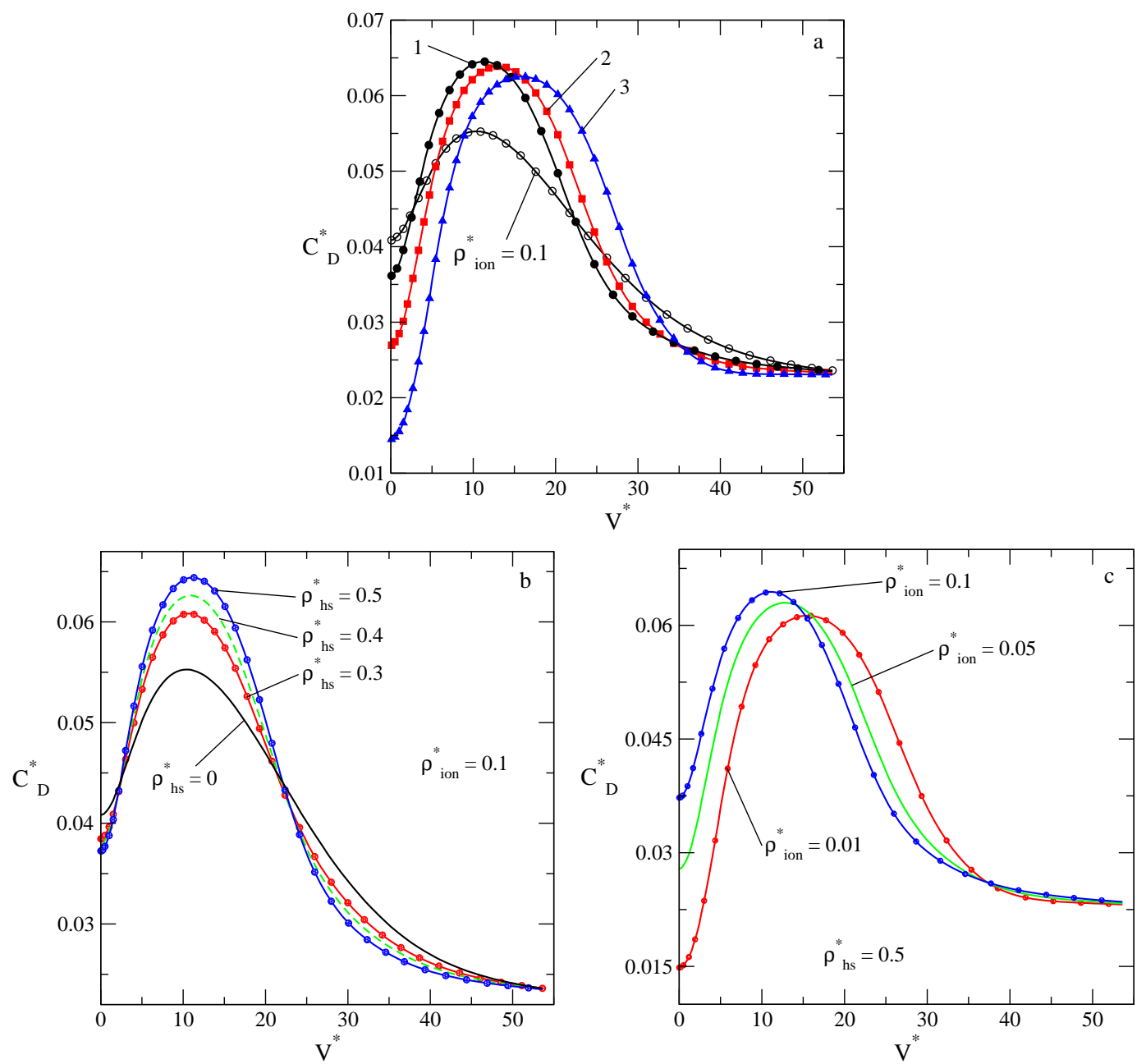

Figure 4. (Color online) The dependences of the differential capacitance, $C_{\mathrm{D}}^{*}$, on the applied voltage, $V^{*}$ at a different bulk fluid density and a different composition shown in each panel. The nomenclature of systems 1,2 , and 3 [panel (a)] is given in the text.

is obtained by taking a derivative of the charge by electrostatic potential on the wall and is plotted as a function of electrostatic potential in figure 4 In all the cases studied we observe the camel-like shape of the differential capacitance. Considering the fixed total density as in figure 3 we see now that the highest maximum value of the capacitance is reached when the ion fraction is the highest, namely for the system 1 compared to 2 and 3 . However, the value of the maximum is less sensitive to the ion fraction compared to the trough at a very small $V^{*}$ [panel (a) of figure 4]. At a very high $V^{*}$ the curves for three systems tend to almost equal value. If we compare the system 1 and its PM counterpart at the same ion density $\left(\rho_{\text {ion }}^{*}=0.1\right)$, then it appears that the differential capacitance curves behave qualitatively similarly. However, in the SPM case, the $C_{\mathrm{D}}^{*}$ maximum is much higher compared to PM. Thus, it seems that the presence of solvent species enhances the separation of ions of the opposite charge by "putting" them slightly closer to the pore walls, where the electric field makes its job. In order to obtain higher values of the differential capacitance at maximum, one can either take a denser solvent (at a fixed ion density) like it is shown in the panel (b) of figure 4 or may increase the ion fraction at a fixed solvent density, like in the panel (c) of figure 4. To summarize, the presence of solvent species in the SPM permits to alter the values of differential capacitance in different regions of $V^{*}$, in comparison to PM. However, the overall shape remains qualitatively similar unless the ion fraction becomes high (in real systems one needs in fact to take into account the solubility limit). 

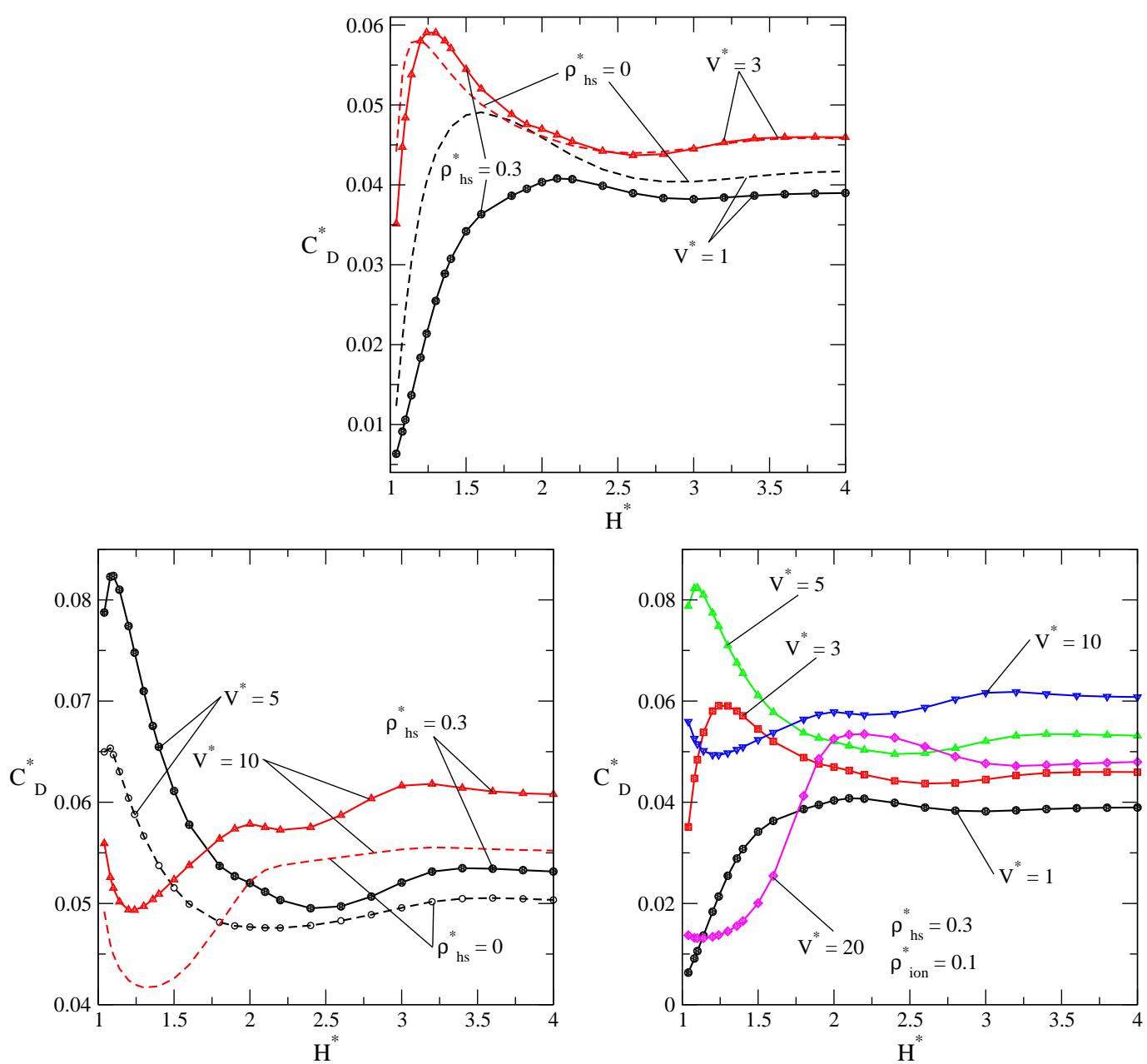

Figure 5. (Color online) The dependences of the differential capacitance, $C_{\mathrm{D}}^{*}$, on the pore width, $H^{*}$ at a different voltage, $V^{*}$. Panels (a) and (b) show a comparison of the results for the SPM and PM at the same conditions. Panel (c) contains the results for $C_{\mathrm{D}}^{*}\left(H^{*}\right)$ solely for the SPM at a different fixed voltage $V^{*}$.

The final issue we would like to discuss is the dependence of the differential capacitance on the pore width. This problem for a restricted primitive model of electrolyte solutions confined in slit-like pores was quite comprehensively discussed in the recent work from this laboratory [19]. In the panel (a) of figure 5 we compare the SPM and PM curves for $C_{\mathrm{D}}^{*}(H)$ at rather low values of the electrostatic potential, namely at $V^{*}=1$ and $V^{*}=3$. The curves for two models are of similar shape. However, the solvent affects the values for $C_{\mathrm{D}}^{*}$, especially in narrow pores. The first maximum of $C_{\mathrm{D}}^{*}$ can be either supressed (at $V^{*}=1$ ) or enhanced (at $V^{*}=3$ ) due to the solvent presence [figure5(a)]. The curves for SPM and PM eventually tend to zero if $H^{*}$ tends to its minimum value.

At higher values of $V^{*}, V^{*}=5$ and $V^{*}=10$ [panel (b) of figure 5], the qualitative features of the shape of functions in question are again similar for SPM and PM. Nevertheless, in the SPM case, we observe more pronounced oscillations of the differential capacitance on the pore width. In other words, the phase of overlap of the density profiles of ions formed at each wall (discussed in detail in [19]) is altered, due to the presence of solvent species. In close similarity to the PM system, the shape of the dependence of $C_{\mathrm{D}}^{*}\left(H^{*}\right)$ in the present SPM case alters depending on the value of the electrostatic potential $V^{*}$. The differential capacitance can either grow or drop in the region of very narrow pores depending on the choice of the voltage. Still, the oscillatory behavior (showing well pronounced and less pronounced maxima and several troughs) is observed for the confined SPM.

It is interesting to mention that Oleksy and Hansen observed the oscillatory curve for the solvation 
force between charged plates with the SPM-like solution in between. However, their calculations were performed under the condition of a constant charge on the plates rather than at a constant potential carried out in the present study. It seems that to establish the relation between the oscillatory curve for the differential capacitance and the dependence of the solvation force on the charged plates separation is of utmost importance in future research. In addition, we would like to emphasize that the model of this study permits several extensions. One of the promising extensions is the possibility to improve the model by introducing the concepts of chemical association in order to deal with the adsorption of either chain molecules or the network-forming solvent. Theoretical background is rather straightforward to be developed along the lines presented in e.g., [34].

\section{Acknowledgements}

O.P. is grateful to David Vazquez for technical assistance at the Institute of Chemistry of the UNAM.

\section{References}

1. Grimson M.J., Rickayzen G., Chem. Phys. Lett., 1982, 86, 71; doi 10.1016/0009-2614(82)83119-9

2. Groot R.D., Phys. Rev. A, 1985, 37, 3456; doi 10.1103/PhysRevA.37.3456.

3. Tang Z., Scriven L.E., Davis H.T., J. Chem. Phys., 1992, 97, 494; doi 10.1063/1.463595

4. Oleksy A., Hansen J.-P., Molec. Phys., 2006, 104, 2871; doi $10.1080 / 00268970600864491$

5. Boda D., Henderson D., J. Chem. Phys., 2000, 112, 8934; doi 10.1063/1.481507

6. Lamperski S., Zydor A., Electrochim. Acta, 2007, 52, 2429; doi 10.1016/j.electacta.2006.08.045

7. Boda D., Henderson D., Patrykiejew A., Sokolowski S., J. Chem. Phys., 2000, 113, 802; doi 10.1063/1.481855

8. Boda D., Henderson D., Patrykiejew A., Sokolowski S., J. Colloid Interface Sci., 2001, 239, 432; doi $10.1006 /$ jcis.2001.7560

9. Henderson D., Bryk P., Sokolowski S., Wasan D.T., Phys. Rev. E, 2000, 61, 3896; doi 10.1103/PhysRevE.61.3896

10. Chmiola J., Yushin G., Gogotsi Y., Portet C., Simon P., Taberna P.L., Science, 2006, 313, 1760; doi $10.1126 /$ science.1132195

11. Largeot C., Portet C., Chmiola J., Taberna P.L., Gogotsi Y., Simon P., J. Am. Chem. Soc., 2008, 130, 2730; doi $10.1021 /$ ja7106178

12. Merlet C., Rotenberg B., Madden P.A., Tabrna P.L., Simon P., Gogotsi Y., Salanne M., Nat. Mater., 2012, 11, 306; doi $10.1038 /$ nmat3260

13. Georgi N., Kornyshev A., Fedorov M., J. Electroanal. Chem., 2010, 649, 261; doi 10.1016/j.jelechem.2010.07.004

14. Kondrat S., Georgi N., Fedorov M., Kornyshev A., Phys. Chem. Chem. Phys., 2011, 13, 11359; doi $10.1039 / \mathrm{c} 1 \mathrm{cp} 20798 \mathrm{a}$

15. Wu P., Huang J., Mernier V., Sumpter B.G., Qiao R., J. Phys. Chem. Lett., 2012, 3, 1732; doi 10.1021/jz300506j

16. Feng G., Cummings P.T., J. Phys. Chem. Lett., 2011, 2, 2859; doi 10.1021/jz201312e

17. Wang Z., Liu L., Neretnieks I., J. Phys.: Condens. Matter, 2011, 23, 175002; doi 10.1088/0953-8984/23/17/175002

18. Wang Z., Liu L., Neretnieks I., J. Chem. Phys., 2011, 135, 244107; doi 10.1063/1.3672001

19. Pizio O., Sokołowski S., Sokołowska Z., J. Chem. Phys., 2012, 137, 234705; doi 10.1063/1.4771919

20. Pizio O., Sokołowski S., J. Chem. Phys., 2013, 138, 204715; doi 10.1063/1.4807777

21. Jiang D., Jin Z., Wu J., Nano Lett., 2011, 11, 5372; doi 10.1021/nl202952d

22. Henderson D., J. Colloid Interface Sci., 2012, 374, 345; doi 10.1016/j.jcis.2012.01.050

23. Bryk P., Sokołowski S., J. Chem. Phys., 2004, 121, 11314; doi 10.1063/1.1814075.

24. Henderson D., Bryk P., Sokołowski S., Wasan D.T., Phys. Rev. E, 2000, 61, 3896; doi 10.1103/PhysRevE.61.3896

25. Kovacs R., Valisko M., Boda D., Condens. Matter Phys., 2012, 15, 23803; doi 10.5488/CMP.15.23803

26. Yu Y.-X., Wu J., J. Chem. Phys., 2002, 117, 2368; doi 10.1063/1.1491240.

27. Yu Y.-X., Wu J., J. Chem. Phys., 2002, 117, 10156; doi 10.1063/1.1520530.

28. Yu Y.-X., Wu J., J. Chem. Phys., 2003, 118, 3835; doi 10.1063/1.1539840.

29. Rosenfeld Y., Phys. Rev. Lett., 1989, 63, 980; doi 10.1103/PhysRevLett.63.980

30. Rosenfeld Y., Phys. Rev. A, 1990, 42, 5978; doi 10.1103/PhysRevA.42.5978

31. Oleksy A., Hansen J.-P., Molec. Phys., 2009, 107, 2609; doi $10.1080 / 00268970903469022$

32. Oleksy A., Hansen J.-P., J. Chem. Phys., 2010, 132, 204702; doi 10.1063/1.3428704

33. Oleksy A., Hansen J.-P., Molec. Phys., 2011, 109, 1275; doi 10.1080/00268976.2011.554903

34. Bryk P., Sokołowski S., Pizio O., J. Chem. Phys., 2006, 125, 024909; doi 10.1063/1.2212944 


\title{
Примітивна модель розчинника подвійного електричного шару в щілиноподібній порі: мікроскопічна структура, адсорбція та електроємність з використанням методу функціоналу густини
}

\author{
О. Пізіо ${ }^{1}$, С. Соколовск²
}

1 Інститут хімії, Національний автономний університет м. Мехіко, Мехіко, Мексика

2 Відділ моделювання фізико-хімічних процесів, Університет Марії Кюрі-Склодовської, Люблін, Польща

\begin{abstract}
Ми досліджуємо електричний подвійний шар, сформований між двома зарядженими стінками щілиноподібної пори, і примітивну модель розчинника для розчину електроліту. Недавно розвинута версія методу зваженого функціоналу густини для електростатичної міжчастинкової взаємодії застосовується до вивчення профілів густини, адсорбції і селективності адсорбованих іонів і компонентів розчинника. Ми звертаємо основну нашу увагу, проте, на залежність диференційної електроємності від прикладеної напруги на електродах і в порі. Ми обговорюємо властивості моделі по відношенню до поведінки примітивної моделі, а саме, у відсутності твердокулькового розчинника. Ми спостерегли, що диференційна електроємність примітивної моделі розчинника при прикладеному електростатичному потенціалі має "двогорбову" форму, незважаючи на високу концентрацію іонів. Крім того, знайдено, осцилюючу залежність диференційної ємності примітивної моделі розчинника від ширини пори, що є дуже подібно до примітивної моделі.
\end{abstract}

Ключові слова: примітивна модель розчинника, функціонал густини, розчини електролітів, адсорбція, диференційна електроємність 